\title{
Cárie rampante de mamadeira em erianças de 2 a 5 anos: revisão de literatura
}

\author{
|Rampant caries of bottle-feeding in children 2 to 5 years: literature review
}

\author{
Lueimar Noleto de Rezende ${ }^{1}$ \\ Felipe César Stabnow Santos ${ }^{2}$ \\ Marcelino Santos Neto ${ }^{3}$ \\ Floriacystabnow Santos ${ }^{4}$
}

\begin{abstract}
Resumo
A falta de informação dos pais sobre a necessidade de higiene dos dentes que estão irrompendo faz com que eles permitam que seus filhos adormeçam durante, ou logo após, a alimentação. Pesquisa exploratóriautilizando a revisão bibliográfica, realizada em janeiro de 2013, objetivando ampliar o conhecimento sobre a cárie rampante de mamadeira, sua etiologia, características clínicas, tratamento e medidas preventivas. Realizada busca na Biblioteca Virtual de saúde, SciELO, PubMed e Google acadêmico usando-se os seguintes descritores: "cárie rampante", "cárie na infância" e "cárie precoce" em artigos publicados entre os anos de 1967 a 2011. Após leitura dos trabalhos selecionados, constatou-se que os autores são unânimes em afirmar que as cáries rampantes são um problema de difícil solução após sua instalação; e que programas de orientação às mães devem ser desenvolvidos, buscando minimizar seu aparecimento nas crianças, com a higienização bucal após cada mamada, desencorajando o uso de mamadeiras e de chupetas açucaradas, e instaurando profilaxia precocemente.
\end{abstract}

\section{Abstraet}

The lack of information from parents about the need of hygiene of erupting teeth causes they allow their children to fall asleep during or soon after feeding. Exploratory research using the literature review, held in January 2013, aiming to extend the knowledge about the rampant caries of bottle, its etiology, clinical features, treatment and preventive measures. Conducted Virtual Health Library search, SciELO, PubMed and Google Scholar using the following keywords: "rampant caries", "early childhood caries" and "early caries" in articles published between the years of 1967 to 2011. After reading selected works, we found that the authors are unanimous in stating that the rampant caries are a problem of difficult solution after its installation, and that orientation programs should be developed for mothers, seeking to minimize its occurrence in children, as the oral hygiene after each feeding, discouraging the use of bottles and pacifiers, and early prophylaxis of sugary.

\section{Deseritores: Cárie Dentária; Mamadeira; Lactente}

Keywords: Dental Caries; Bottle; Infant

\author{
'Odontóloga, Especialista em Saúde da Familia. \\ ${ }^{2}$ Enfermeiro, Hospital Universitário da Universidade de Brasilia-DF.
${ }^{3}$ Farmacêutieo, Professor Assistente da Universidade Federal do Maranhão/Centro de Ciêneias Sociais, Saiude e Teenologia, Doutorando em Enfermagem em Saúde Pública pela Escola de Enfermagem de Rihbirão Preto/Universidade de São Paulo

\begin{abstract}
4 Enfermeira, Professora Assistente da Universidade Federal do Maranhão/Centro de Ciências Sociais, Saúde e Teenologia, Doutoranda em Enfermagem em Saúde Pública pela Escola de Enfermagem de Ribeirão Preto/Universidade de São Paulo
\end{abstract}

Para correspondência:

Floriacy Stabnow Santos

E-mail:floriacys@gmail.com 
Introducã̃o

O aleitamento materno é uma ação de grande importância para a diminuição das taxas de morbimortalidade infantil. Trata-se de um ato insubstituível, visto que o leite materno é o mais completo alimento, em termos de qualidade nutricional, sendo a forma mais segura e barata de se garantir um bom estado de saúde para o bebê $(1,2)$. No entanto, a higiene oral após as mamadas é muito importante, especialmente após a introdução da mamadeira com alimentos e líquidos açucarados, que podem contribuir para a formação de cáries e causar uma severa destruição dos dentes decíduos (3).

A cárie dentária é considerada um problema de saúde pública nas populações desde o início do século XX. No entanto, estudos sistemáticos no Brasil só ocorreram após a década de 1950, para justificar a intervenção em saúde $\operatorname{bucal}^{(4)}$.

A prevalência de cárie em bebês é alta (em torno de $55 \%$ ), principalmente na faixa etária de zero a 30 meses, demonstrando a necessidade de medidas preventivas, educativas e restauradoras para essa faixa etária. Gestantes e mães compõem o público-alvo para receber orientação, pelo fato de serem as maiores responsáveis pela alimentação e pelos cuidados com a higiene da criança(5).

A cárie dentária pode progredir até a destruição total das estruturas mineralizadas, caso não seja tratada a tempo. Fatores sociais, culturais e comportamentais estão envolvidos nesse processo, em especial os hábitos alimentares e de higiene bucal(6).

Os pais precisam ser informados sobre a necessidade de higiene dos dentes que estão irrompendo, bem como sobre o potencial cariogênico do leite em horários frequentes, pois este fica estagnado sobre os dentes, proporcionando um excelente meio de cultura aos micro-organismos acidogênicos da cavidade bucal. Dessa forma, os pais não devem permitir que seus filhos adormeçam durante, ou logo após, serem alimentados ${ }^{(7)}$.

A cárie rampante tem evolução rápida e agressiva, e pode envolver muitos ou até todos os dentes; já a cárie de mamadeira ocorre na dentição decídua (dente de leite) de crianças que usam mamadeiras com alimentos açucarados enquanto dormem. As lesões de cárie ocorrem normalmente nos dentes superiores; os inferiores geralmente não apresentam cárie e, quando apresentam, são de pequenas proporções. Isso se deve ao fato de a língua se interpor entre os dentes inferiores e o leite, ou líquido açucarado ingerido, protegendo-os relativamente contra a desmineralização severa do esmalte dental (8).

A saúde bucal deve ser preocupação de todo profissional de saúde e, em especial, do médico pediatra, que deve identificar hábitos que possam ser prejudiciais para a criança e orientar os pais para que procurem o auxílio do dentista o quanto antes, evitando os efeitos destrutivos da cárie de mamadeira ${ }^{(9)}$.

Considerando-sea importância das manifestações bucais e sua repercussão na Qualidade de Vida do paciente infantil, além das dificuldades na alimentação deste e o advento da terapia restauradora, o presente trabalho se propôs a investigara doença cárie por meio de uma revisão da literatura. Este trabalho objetivou ampliar o conhecimento sobre a cárie rampante de mamadeira, sua etiologia e suas características clínicas, analisando os principais métodos utilizados para o tratamento e descrevendo as principais medidas preventivas no combate ao aparecimento e à evolução das cáries rampantes de mamadeira.

\section{Metodologia}

Trata-se de uma pesquisa exploratória,utilizando a revisão bibliográfica para ampliar o conhecimento sobre a cárie rampante de mamadeira e sua etiologia, bem como o tratamento conservador em crianças de 0 a 5 anos de idade. A pesquisa foi realizada em janeiro de 2013.

Foi feita uma busca na internet nas bases de dados da Biblioteca Virtual de saúde, Scielo, PubMed e Google acadêmico usando-se os seguintes descritores: "cárie rampante", "cárie na infância" e "cárie precoce". Foram encontrados 38 trabalhos que abordavam o assunto e destes foram selecionados 24 publicações. Para a inclusão dos artigos, foram usados os seguintes critérios: periódicos publicados entre o período de 1962 a 2011; periódicos publicados no português ou inglês; periódicos disponibilizados na íntegra ou resumos; trabalhos que envolviam crianças na faixa etária de 0 a 5 anos. 


\section{Resultados}

Foram selecionados 24 artigos que atendiam os critérios. Após leitura e fichamento, procedeu-se à síntese dos dados encontrados mostrados no quadro 1.

\begin{tabular}{|c|c|c|c|c|c|c|}
\hline No. & Autor & Título & Etilogia & Características & Tratamento & $\begin{array}{l}\text { Medidas } \\
\text { preventivas }\end{array}$ \\
\hline 1 & $\begin{array}{l}\text { Ramos BC, } \\
\text { et al. (10) }\end{array}$ & $\begin{array}{lr}\text { Cárie } & \text { tipo } \\
\text { mamadeira e } & \text { a } \\
\text { importância } & \text { de } \\
\text { saúde bucal em } \\
\begin{array}{llll}\text { crianças de } & 0 & \text { a } & 4 \\
\text { anos }\end{array}\end{array}$ & $\begin{array}{l}\text { Amamentação } \\
\text { noturna, nascimento } \\
\text { prematuro, doença } \\
\text { sistêmica, contato } \\
\text { prévio com fluoreto }\end{array}$ & $\begin{array}{lr}\text { As } & \text { cáries } \\
\text { exclusivas } & \text { do } \\
\text { aleitamento } & \\
\text { materno são as } \\
\text { menos graves e } \\
\text { extensas }\end{array}$ & $\begin{array}{ll}\text { Controle } & \text { da } \\
\text { dieta e } & \\
\text { controle } & \text { de } \\
\text { placa } & \end{array}$ & $\begin{array}{l}\text { Educação para a } \\
\text { saúde bucal, } \\
\text { higiene oral } \\
\text { antes de dormir }\end{array}$ \\
\hline 2 & $\begin{array}{l}\text { Ribeiro } \\
\text { EMN, et al. } \\
(11)\end{array}$ & $\begin{array}{l}\text { Aleitamento } \\
\text { materno e cárie do } \\
\text { lactente e do pré- } \\
\text { escolar: uma } \\
\text { revisão crítica. }\end{array}$ & $\begin{array}{l}\text { microrganismos } \\
\text { criogênicos, }\end{array}$ & $\begin{array}{l}\text { Não há evidências } \\
\text { científicas que } \\
\text { comprovem que o } \\
\text { leite materno possa } \\
\text { estar associado } \\
\text { com o surgimento } \\
\text { de cáries }\end{array}$ & $\begin{array}{l}\text { Visita precoce e } \\
\text { frequente ao } \\
\text { dentista }\end{array}$ & $\begin{array}{l}\text { Escovação } \\
\text { dentária com } \\
\text { dentifrício } \\
\text { fluoretado e a } \\
\text { escovação antes } \\
\text { de dormir }\end{array}$ \\
\hline 3 & $\begin{array}{l}\text { Award LP, } \\
\text { et al. (12) }\end{array}$ & $\begin{array}{l}\text { Cárie provocada } \\
\text { por leite materno: } \\
\text { revisão e } \\
\text { apresentação de } \\
\text { caso clínico }\end{array}$ & $\begin{array}{l}\text { Consumo } \\
\text { de leite materno em } \\
\text { regime de livre } \\
\text { demanda, } \\
\text { associado à ingestão } \\
\text { frequente de } \\
\text { carboidratos } \\
\text { fermentáveis. }\end{array}$ & $\begin{array}{l}\text { A doença } \\
\text { cárie que afeta a } \\
\text { dentição decídua, } \\
\text { está associada ao } \\
\text { uso } \\
\text { prolongado de } \\
\text { mamadeira } \\
\text { contendo leite ou } \\
\text { fórmula de leite, } \\
\text { suco de fruta ou } \\
\text { água açucarada }\end{array}$ & $\begin{array}{l}\text { Abordagem } \\
\text { individualizada } \\
\text { para cada caso }\end{array}$ & $\begin{array}{l}\text { Educação do } \\
\text { núcleo familiar, } \\
\text { para criação de } \\
\text { novos hábitos } \\
\text { alimentares e de } \\
\text { higiene bucal }\end{array}$ \\
\hline 4 & $\begin{array}{l}\text { Kroll RG, } \\
\text { et al. (13) }\end{array}$ & $\begin{array}{l}\text { Nocturnal bottle } \\
\text { feeding as a } \\
\text { countributory } \\
\text { cause of rampant } \\
\text { dental caries in the } \\
\text { infant and young } \\
\text { child }\end{array}$ & $\begin{array}{l}\text { Mamadeiras com } \\
\text { açúcar oferecidas à } \\
\text { noite }\end{array}$ & 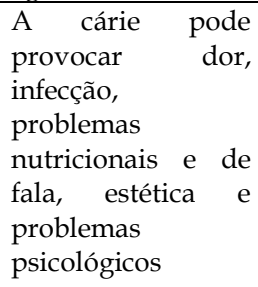 & $\begin{array}{l}\text { Restauração } \\
\text { dos dentes } \\
\text { afetados } \\
\text { e,suspensão } \\
\text { das } \\
\text { mamadeiras } \\
\text { noturnas }\end{array}$ & $\begin{array}{l}\text { Higienização } \\
\text { dos dentes }\end{array}$ \\
\hline 5 & $\begin{array}{l}\text { Kotlow LA } \\
\text { (14) }\end{array}$ & $\begin{array}{l}\text { Breast feeding: a } \\
\text { cause } \\
\text { dentalcaries In } \\
\text { children. Journal } \\
\text { dent Child }\end{array}$ & $\begin{array}{l}\text { Mamadas noturnas } \\
\text { com leite açucarado }\end{array}$ & $\begin{array}{l}\text { A cárie de } \\
\text { mamadeira é uma } \\
\text { doença aguda, que } \\
\text { afeta a dentição } \\
\text { decídua } \\
\text { crianças em seus } \\
\text { primeiros } 12 \text { meses } \\
\text { de vida }\end{array}$ & $\begin{array}{l}\text { Visita frequente } \\
\text { ao dentista } \\
\text { para } \\
\text { restauração dos } \\
\text { dentes afetados }\end{array}$ & $\begin{array}{l}\text { Higiene oral } \\
\text { frequente }\end{array}$ \\
\hline 6 & $\begin{array}{l}\text { Gardner } \\
\text { DE, et al. } \\
(15)\end{array}$ & $\begin{array}{l}\text { At will breast } \\
\text { feeding and dental } \\
\text { caries: four case } \\
\text { reports. }\end{array}$ & $\begin{array}{lr}\text { Uso prolongado } & \text { de } \\
\text { alimentação } & \text { por } \\
\text { mamadeiras } & \end{array}$ & $\begin{array}{l}\text { A cárie acomete os } \\
\text { incisivos centrais e } \\
\text { laterais superiores, } \\
\text { primeiros molares } \\
\text { e caninos }\end{array}$ & $\begin{array}{l}\text { Diminuir a } \\
\text { ingestão de } \\
\text { açúcar ou de } \\
\text { uso prolongado } \\
\text { de } \\
\text { amamentação } \\
\text { noturna }\end{array}$ & $\begin{array}{l}\text { Colocar a criança } \\
\text { para arrotar } \\
\text { após a } \\
\text { amamentação e } \\
\text { higiene após as } \\
\text { mamadas }\end{array}$ \\
\hline 7 & $\begin{array}{l}\text { Abbey LM } \\
\text { (16) }\end{array}$ & $\begin{array}{l}\text { Is breast feeding a } \\
\text { likely cause of } \\
\text { dental caries in } \\
\text { young children? }\end{array}$ & Mamadeirasaçucaradas & $\begin{array}{l}\text { Mamadas noturnas } \\
\text { é a causa principal } \\
\text { da deterioração } \\
\text { dos dentes }\end{array}$ & $\begin{array}{l}\text { Visita precoce } \\
\text { ao dentista, } \\
\text { suspender } \\
\text { mamadeiras } \\
\text { noturnas, uso } \\
\text { de água } \\
\text { fluoretada }\end{array}$ & $\begin{array}{lr}\text { Orientar os pais } \\
\text { sobre } \\
\text { importância da } \\
\text { higiene } \\
\text { frequente }\end{array}$ \\
\hline
\end{tabular}




\begin{tabular}{|c|c|c|c|c|c|c|}
\hline 8 & $\begin{array}{l}\text { Ripa LW } \\
(17)\end{array}$ & $\begin{array}{l}\text { Nursing caries: a } \\
\text { comprehensive } \\
\text { review. }\end{array}$ & $\begin{array}{l}\text { Hábito da criança } \\
\text { adormecer } \\
\text { mamando, uso de } \\
\text { chupeta açucarada, } \\
\text { uso de xaropes } \\
\text { e/ou vitaminas } \\
\text { açucarados }\end{array}$ & $\begin{array}{lr}\text { cárie rampante, } \\
\text { afeta a oclusão dos } \\
\text { primeiros }\end{array}$ & $\begin{array}{l}\text { Visita frequente } \\
\text { ao dentista }\end{array}$ & $\begin{array}{l}\text { Higiene oral após } \\
\text { mamadas }\end{array}$ \\
\hline 9 & $\begin{array}{l}\text { Costa } \\
\text { ICC }(18)\end{array}$ & $\begin{array}{l}\text { Atenção } \\
\text { odontológica a } \\
\text { gestantes na } \\
\text { concepção } \\
\text { médico-dentista- } \\
\text { paciente: } \\
\text { representações } \\
\text { sociais dessa } \\
\text { interação }\end{array}$ & $\begin{array}{l}\text { Falta de } \\
\text { tratamento } \\
\text { odontológico } \\
\text { durante a gravidez }\end{array}$ & $\begin{array}{l}\text { A família } \\
\text { representa o núcleo } \\
\text { mais primitivo, no } \\
\text { qual se formam e se } \\
\text { desenvolvem } \\
\text { hábitos, atitudes e } \\
\text { comportamentos } \\
\text { que serão } \\
\text { reproduzidos } \\
\text { durante toda a vida }\end{array}$ & $\begin{array}{l}\text { Visita ao } \\
\text { dentista durante } \\
\text { a gestação }\end{array}$ & $\begin{array}{lr}\text { Disseminar } & \text { noções } \\
\text { de higiene } & \text { bucal, } \\
\text { realizar } & \text { trabalho } \\
\text { educativo } & \text { em } \\
\text { saúde } & \text { bucal } \\
\text { dirigido } & \text { às } \\
\text { gestantes } & \end{array}$ \\
\hline 10 & $\begin{array}{l}\text { Corsetti } \\
\text { LO, et al. } \\
\text { (19) }\end{array}$ & $\begin{array}{lr}\text { Avaliação } & \text { do } \\
\text { atendimento } \\
\text { para gestantes } \\
\text { nos serviços } \\
\text { públicos de Porto } \\
\text { Alegre - RS, } \\
\text { duranter } \\
\text { período } \\
\text { natal. }\end{array}$ & $\begin{array}{lr}\text { Dificuldade } & \text { de } \\
\text { sensibilização } & \text { da } \\
\text { gestante sobre } & \text { a } \\
\text { importância } & \text { da } \\
\text { prevenção } & \end{array}$ & $\begin{array}{l}\text { Nem sempre as } \\
\text { gestantes se } \\
\text { sensibilizam com o } \\
\text { problema da saúde } \\
\text { bucal }\end{array}$ & \begin{tabular}{l}
\multicolumn{3}{l}{ Criar percepção } \\
quanto $\quad$ ao \\
problema e à \\
medida \\
preventiva \\
em questão.
\end{tabular} & $\begin{array}{l}\text { Implantação de } \\
\text { programas } \\
\text { preventivos } \\
\text { educativos } \\
\text { gestantes, } \\
\text { introduzir bons } \\
\text { hábitos desde o } \\
\begin{array}{l}\text { início da vida da } \\
\text { criança }\end{array}\end{array}$ \\
\hline 11 & $\begin{array}{l}\text { Freitas } \\
\text { DA, et al. } \\
\text { (20) }\end{array}$ & $\begin{array}{l}\text { Saúde bucal de } \\
\text { gestantes: } \\
\text { enfoque em } \\
\text { saúde pública. }\end{array}$ & $\begin{array}{l}\text { Aumento dos } \\
\text { hormônios } \\
\text { femininos } \\
\text { circulantes durante } \\
\text { a gestação e e } \\
\text { exacerbação da } \\
\text { reação } \\
\text { inflamatória } \\
\text { gengival, } \\
\text { principalmente por } \\
\text { sua ação } \\
\text { vasodilatadora }\end{array}$ & $\begin{array}{l}\text { A gestação } \\
\text { intensifica a reação } \\
\text { inflamatória no } \\
\text { tecido gengival, o } \\
\text { biofilme dentário - } \\
\text { acúmulo de } \\
\text { bactérias no dente }\end{array}$ & $\begin{array}{l}\text { Controle por } \\
\text { meio } \\
\text { escovação de } \\
\text { apropriada evita } \\
\text { inflamação e } \\
\text { sangramentoe } \\
\begin{array}{l}\text { educação em } \\
\text { saúde bucal }\end{array}\end{array}$ & $\begin{array}{l}\text { Discutir com as } \\
\text { grávidas a } \\
\text { importância de } \\
\text { uma boa nutrição } \\
\text { durante a gestação }\end{array}$ \\
\hline 12 & $\begin{array}{l}\text { Konishi } \\
\text { MFCC (21) }\end{array}$ & \begin{tabular}{lr}
\multicolumn{2}{l}{ Odontologia } \\
intra-uterina: a \\
construção \\
saúde da \\
antes bucal \\
nascimento
\end{tabular} & $\begin{array}{l}\text { A cárie passa de } \\
\text { mãe para filho, não } \\
\text { só pela } \\
\text { contaminação } \\
\text { primária, mas } \\
\text { principalmente } \\
\text { pela transmissão } \\
\text { de hábitos } \\
\text { inadequados }\end{array}$ & $\begin{array}{lr}\text { A literatura } & \text { não } \\
\text { demonstra } & \text { um } \\
\text { aumento } & \text { da } \\
\text { incidência de cárie } \\
\text { em } \quad \text { mulheres } \\
\text { grávidas }\end{array}$ & $\begin{array}{l}\text { Orientações } \\
\text { devem incluir } \\
\text { uso racional do } \\
\text { flúor e cuidados } \\
\text { com a saúde } \\
\text { bucal do bebê e } \\
\text { modificar a } \\
\text { microbiota da } \\
\text { mãe para que se } \\
\text { torne } \\
\text { compatível com } \\
\text { saúde }\end{array}$ & $\begin{array}{l}\text { Educar gestantes } \\
\text { sobre as causas e } \\
\text { condições em que } \\
\text { as cáries se } \\
\text { desenvolvem, seus } \\
\text { meios } \\
\text { transmissão }\end{array}$ \\
\hline
\end{tabular}




\begin{tabular}{|c|c|c|c|c|c|c|}
\hline 13 & $\begin{array}{l}\text { Menoli } \\
\text { APV, et } \\
\text { al. (22) }\end{array}$ & 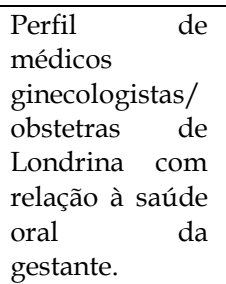 & $\begin{array}{l}\text { As gestantes formam um } \\
\text { grupo altamente susceptível } \\
\text { a receber informações e } \\
\text { incorporar novas atitudes }\end{array}$ & $\begin{array}{l}\text { Na gestação as } \\
\text { mulheres } \\
\text { incorporam as } \\
\text { informações sobre } \\
\text { saúde melhor do } \\
\text { que em qualquer } \\
\text { outro período de } \\
\text { sua vida. }\end{array}$ & $\begin{array}{l}\text { Tratamento } \\
\text { preventivo }\end{array}$ & $\begin{array}{l}\text { Educação em } \\
\text { saúde bucal }\end{array}$ \\
\hline 14 & $\begin{array}{l}\text { Costa } \\
\text { ICC, et } \\
\text { al. (23) }\end{array}$ & $\begin{array}{l}\text { A gestante } \\
\text { como agente } \\
\text { multiplicador } \\
\text { de saúde. }\end{array}$ & 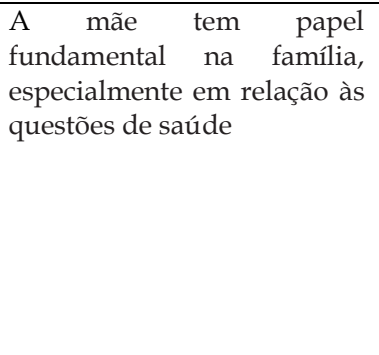 & $\begin{array}{lr}\text { É relevante } & \text { a } \\
\text { implantação } & \text { de } \\
\text { programas } & \text { que } \\
\text { venham } & \text { a } \\
\text { interferir } & \text { na } \\
\text { quebra da cadeia } \\
\text { de } \\
\text { transmissibilidade } \\
\text { da cárie }\end{array}$ & $\begin{array}{l}\text { Mãe/gestante } \\
\text { possa atuar } \\
\text { como agente } \\
\text { multiplicador } \\
\text { de } \\
\text { informações } \\
\text { de promoção } \\
\text { de sua saúde } \\
\text { e de sua } \\
\text { família }\end{array}$ & $\begin{array}{l}\text { Medidas } \\
\text { preventivo- } \\
\text { educativas }\end{array}$ \\
\hline 15 & $\begin{array}{l}\text { Fass } \\
\text { EN (24) }\end{array}$ & $\begin{array}{l}\text { Is bottle feeding } \\
\text { a factor in } \\
\text { dental caries? }\end{array}$ & Criançasdormindomamando & $\begin{array}{l}\text { As lesões de } \\
\text { cáries, raramente } \\
\text { atingem os } \\
\text { incisivos inferiores } \\
\text { decíduosporque, } \\
\text { durante a sucção, } \\
\text { a língua estende- } \\
\text { se sobre esses } \\
\text { dentes } \\
\text { protegendo-os da } \\
\text { ação das } \\
\text { substâncias } \\
\text { cariogênicas }\end{array}$ & $\begin{array}{l}\text { Visita precoce } \\
\text { ao dentista }\end{array}$ & $\begin{array}{l}\text { Orientação } \\
\text { sobre saúde } \\
\text { bucal }\end{array}$ \\
\hline 16 & $\begin{array}{l}\text { Goldie } \\
\text { MP (25) }\end{array}$ & $\begin{array}{l}\text { Oral health care } \\
\text { for pregnant } \\
\text { and } \\
\text { postpartum } \\
\text { women }\end{array}$ & $\begin{array}{l}\text { Gravidez pode representar } \\
\text { uma série de preocupações } \\
\text { para a mãe }\end{array}$ & 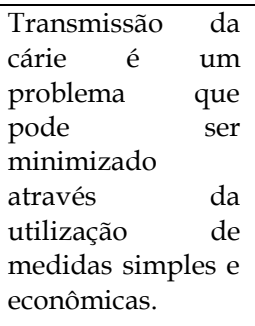 & $\begin{array}{l}\text { Minimizar os } \\
\text { resultados } \\
\text { adversos da } \\
\text { gestação e o } \\
\text { risco de cárie } \\
\text { em seus filhos }\end{array}$ & $\begin{array}{l}\text { Medidas } \\
\text { educacionais } \\
\text { e preventivas } \\
\text { para as mães }\end{array}$ \\
\hline 17 & $\begin{array}{l}\text { Menino } \\
\text { RTM, } \\
\text { et al. (26) }\end{array}$ & $\begin{array}{l}\text { Necessidades } \\
\text { de saúde bucal } \\
\text { em gestantes } \\
\text { dos núcleos de } \\
\text { saúde de } \\
\text { Bauru. } \\
\text { Conhecimentos } \\
\text { com relação à } \\
\text { própria saúde } \\
\text { bucal }\end{array}$ & $\begin{array}{l}\text { Elevada acidez da cavidade } \\
\text { oral induz a proliferação } \\
\text { microbiana, contribuindo } \\
\text { para o surgimento de cárie }\end{array}$ & $\begin{array}{l}\text { A gestação não é o } \\
\text { fator determinante } \\
\text { para a } \\
\text { perda de minerais } \\
\text { dos dentes }\end{array}$ & $\begin{array}{lr}\text { Visitas } & \text { ao } \\
\text { dentista } & \\
\text { durante } & \text { a } \\
\text { gestação } & \end{array}$ & $\begin{array}{ll}\begin{array}{l}\text { Higiene oral } \\
\text { eficaz }\end{array} & \end{array}$ \\
\hline
\end{tabular}




\begin{tabular}{|c|c|c|c|c|c|c|}
\hline 18 & $\begin{array}{l}\text { Mills } \\
\text { LW, et al. } \\
\text { (27) }\end{array}$ & $\begin{array}{l}\text { Oral health } \\
\text { during } \\
\text { pregnancy }\end{array}$ & $\begin{array}{l}\text { Saúde bucal da gestante } \\
\text { negligenciada }\end{array}$ & $\begin{array}{l}\text { A } \\
\text { periodontal pode } \\
\text { ser um fator de } \\
\text { risco para } \\
\text { prematuridade e } \\
\text { baixo peso ao } \\
\text { nascer }\end{array}$ & 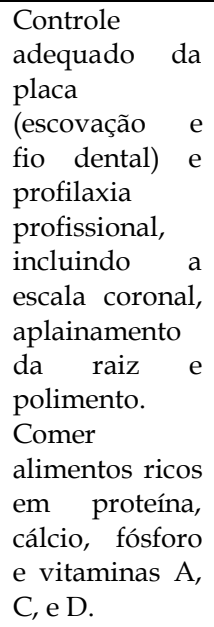 & $\begin{array}{l}\text { Avaliação } \text { da } \\
\text { dentição materna } \\
\text { durante o pré- } \\
\text { natal } \\
\text { encaminhamento } \\
\text { para o dentista em } \\
\text { caso de problemas } \\
\text { dentários }\end{array}$ \\
\hline 19 & $\begin{array}{l}\text { Carvalho } \\
\text { GD }(28)\end{array}$ & $\begin{array}{l}\text { Amamentação: } \\
\text { Uma avaliação } \\
\text { abrangente }\end{array}$ & $\begin{array}{l}\text { A amamentação } \\
\text { promove o correto } \\
\text { desenvolvimento das } \\
\text { estruturas do } \\
\text { sistemaestomatognático, } \\
\text { pois, ao sugar o seio, a } \\
\text { criança } \\
\text { estabelece o padrão } \\
\text { correto de respiração } \\
\text { nasal e } \\
\text { deglutição }\end{array}$ & \begin{tabular}{lr} 
Os & hábitos \\
alimentares & \\
adquiridos pelas \\
crianças & estão \\
relacionados aos \\
da mãe e ao com \\
nível \\
conhecimento de \\
desta a respeito de \\
\multicolumn{2}{l}{ sua saúde }
\end{tabular} & $\begin{array}{l}\text { Durante o pré- } \\
\text { natal, } \\
\text { a mãe deve ter } \\
\text { sido } \\
\text { esclarecida } \\
\text { sobre o } \\
\text { processo } \\
\text { fisiológico da } \\
\text { lactação, } \\
\text { tempo usado } \\
\text { para as } \\
\text { mamadas, do } \\
\text { posição do } \\
\text { bebê ao peito e } \\
\text { composição } \\
\text { química do } \\
\text { leite. }\end{array}$ & $\begin{array}{l}\text { Promoção de } \\
\text { saúde bucal na } \\
\text { primeira infância }\end{array}$ \\
\hline 20 & $\begin{array}{l}\text { Martins } \\
\text { VF (29) }\end{array}$ & $\begin{array}{l}\text { A importância } \\
\text { da odontologia } \\
\text { para as } \\
\text { gestantes }\end{array}$ & Saúde bucal inadequada & $\begin{array}{l}\text { Se a gestante não } \\
\text { possui } \\
\text { uma saúde bucal } \\
\text { adequada e não } \\
\text { compreende o } \\
\text { conceito } \\
\text { de saúde, ela } \\
\text { provavelmente } \\
\text { terá dificuldades } \\
\text { para realizar e } \\
\text { praticar medidas } \\
\text { de prevenção de } \\
\text { doenças e } \\
\text { promoção da sua } \\
\text { saúde bucal }\end{array}$ & $\begin{array}{lr}\text { Medidas } & \text { de } \\
\text { prevenção } & \text { de } \\
\text { doenças } & \mathrm{e} \\
\text { promoção de } \\
\text { sua saúde } \\
\text { bucal }\end{array}$ & $\begin{array}{l}\text { Educação em } \\
\text { saúde bucal com a } \\
\text { gestante }\end{array}$ \\
\hline
\end{tabular}




\begin{tabular}{|c|c|c|c|c|c|c|}
\hline 21 & $\begin{array}{l}\text { Ferreira } \\
\mathrm{CD}^{(30)}\end{array}$ & $\begin{array}{l}\text { Relação entre } \\
\text { questões } \\
\text { nutricionais } \\
\text { cárie dentária }\end{array}$ & $\begin{array}{l}\text { Alterações nos } \\
\text { germes dentários e } \\
\text { a ingestão } \\
\text { frequente de } \\
\text { carboidratos } \\
\text { fermentáveis são } \\
\text { alguns dos } \\
\text { multifatores } \\
\text { associados à cárie } \\
\text { dentária }\end{array}$ & $\begin{array}{l}\text { Apesar do leite, } \\
\text { mesmo sem açúcar, } \\
\text { ser cariogênico, este } \\
\text { também possui } \\
\text { substâncias que } \\
\text { podem proteger o } \\
\text { dente contra as } \\
\text { cáries, como o cálcio } \\
\text { e o fósforo, que } \\
\text { ajudam no processo } \\
\text { de remineralização } \\
\text { do esmalte, e a } \\
\text { caseína, que fornece } \\
\text { uma proteção } \\
\text { orgânica, revestindo } \\
\text { a superfície do } \\
\text { esmalte }\end{array}$ & $\begin{array}{l}\text { Ações } \\
\text { intersetoriais } \\
\text { envolvendo a } \\
\text { odontologia e a } \\
\text { nutrição para se } \\
\text { multidi } \\
\text { sciplinar a } \\
\text { saúde }\end{array}$ & $\begin{array}{l}\text { Ações } \\
\text { promoção } \\
\text { saúde }\end{array}$ \\
\hline 22 & $\begin{array}{l}\text { Roberts } \\
\text { GJ (31) }\end{array}$ & $\begin{array}{l}\text { Is breast feeding } \\
\text { a possible cause } \\
\text { of dental caries? }\end{array}$ & $\begin{array}{l}\text { amamentação dos } \\
\text { bebês como uma } \\
\text { possível causa, } \\
\text { levando a ao } \\
\text { desenvolvimento } \\
\text { de cárie dentária } \\
\text { em crianças. }\end{array}$ & $\begin{array}{l}\text { características } \\
\text { clínicas da cárie de } \\
\text { leite materno; }\end{array}$ & $\begin{array}{l}\text { Consuta com o } \\
\text { dentista }\end{array}$ & $\begin{array}{l}\text { Procurar dentista } \\
\text { precocemente }\end{array}$ \\
\hline 23 & $\begin{array}{l}\text { Seow WK } \\
\text { (32) }\end{array}$ & $\begin{array}{l}\text { Biological } \\
\text { mechanisms of } \\
\text { early childhood } \\
\text { caries }\end{array}$ & $\begin{array}{lr}\text { causada } & \text { por } \\
\text { estreptococos } & \\
\text { mutans } & \text { que } \\
\text { fermentarem } & \\
\text { hidratos } & \text { de } \\
\text { carbono dietéticos } \\
\text { para produzir } \\
\text { ácidos ataques nos } \\
\text { dentes sensíveis } \\
\text { durante r um } \\
\text { período de tempo }\end{array}$ & $\begin{array}{l}\text { A cárie está } \\
\text { relacionada a } \\
\text { implantação da } \\
\text { bactéria cariogênica, } \\
\text { imaturidade dos } \\
\text { sistemas de defesa } \\
\text { do hospedeiro, bem } \\
\text { como padrões } \\
\text { comportamentais } \\
\text { associados com a } \\
\text { alimentação e } \\
\text { higiene bucal na } \\
\text { primeira infância. }\end{array}$ & $\begin{array}{l}\text { Alimentação } \\
\text { adequada, } \\
\text { visitas ao } \\
\text { dentistas }\end{array}$ & $\begin{array}{l}\text { Orientação } \\
\text { saúde bucal }\end{array}$ \\
\hline 24 & $\begin{array}{l}\text { Jin } \mathrm{BH} \text {, et } \\
\text { al. (33) }\end{array}$ & $\begin{array}{l}\text { Early childhood } \\
\text { caries: } \\
\text { prevalence and } \\
\text { risk factors in } \\
\text { Seoul, Korea }\end{array}$ & $\begin{array}{lr}\begin{array}{l}\text { Alimentação } \\
\text { açúcar }\end{array} & \text { com } \\
\text { refeições } & \\
\end{array}$ & $\begin{array}{l}\text { Crianças de } 6-59 \\
\text { meses de idade, tem } \\
\text { prevalência de cárie } \\
\text { de } 56,5 \%\end{array}$ & $\begin{array}{l}\text { Tratar fatores de } \\
\text { risco }\end{array}$ & $\begin{array}{l}\text { Programas de } \\
\text { intervenção } \\
\text { educativa precoce } \\
\text { para as mulheres } \\
\text { grávidas e mães de } \\
\text { crianças pequenas }\end{array}$ \\
\hline
\end{tabular}

Quadro 1. Distribuição de artigos selecionados com título, etiologia, características, tratamento e medidas preventivas. 2013 


\section{Diseussão}

A promoção da saúde bucal das crianças é muito importante, pois prioriza a educação em saúde e prevenção precoce ${ }^{(10)}$. A cárie de mamadeira se desenvolve a partir da associação de mamadas sem controle, que ultrapassam o primeiro ano da criança e em horários livres. Essas mamadas podem ser da mamadeira ou do peito. O aparecimento da lesão de cárie de mamadeira se dá também por alguns hábitos estimulados na criança, como oferecer chupetas adoçadas $(10,11)$.

A confluência de 4 fatores são necessários para a ocorrência da cárie: dentes sensíveis, microflora específica, substratos fermentáveis e tempo. As mamadeiras com leite adoçado, sucos de frutas, refrigerantes e leite bovino são potenciais promotores de cárie. Apesar de numerosos estudos demonstrarem que o leite bovino contém fatores orgânicos e inorgânicos protetores de cárie, ele também contém lactose que pode servir como substrato para estreptococo mutans ${ }^{(17)}$.Entretanto, as mamadas noturnas são as grandes causadoras da cárie rampante de mamadeira ${ }^{(12)}$, resultado do efeito local da impregnação do leite e de agentes açucarados nos dentes ${ }^{(13,14)}$.

Além da destruição da estrutura dentária, a cárie pode provocar dor, infecção, problemas nutricionais e de fala, estética e problemas psicológicos, sendo que o tratamento consiste na restauração dos dentes afetados e, principalmente, na suspensão do hábito deletério. Deve existir, então, uma interação entre odontopediatras e pais, com o intuito de alertar estes a respeito da afecção, procurando demonstrar que uma nutrição adequada da criança pode ser adquirida enquanto ela está acordada, para que seja possível a higienização de seus dentes ${ }^{(13)}$.

A cárie rampante afeta a dentição decídua de crianças em seus primeiros 12 meses de vida $(10,11,14)$, mas os incisivos inferiores e segundos molares geralmente não são afetados, somente em casos mais severos, de grande ingestão de açúcar ou de uso prolongado de amamentação noturna, de forma que a criança deve ser colocada para arrotar após a amamentaçãoe a higienização dos dentes deve ser realizada após cada mamada(15).

As principais características da cárie de mamadeira são: cárie rampante na superfície palatina dos incisivos centrais superiores se estendendo para a distal, afetando também a oclusão dos primeiros e segundos molares superiores, superfície vestibular dos caninos e molares inferiores; em casos severos, a coroa de todos os dentes é destruída, com exceção dos incisivos inferiores $(16,17)$.

A atuação dos pais é muito importante. Eles devem ser orientados a complementar a alimentação com outros alimentos e suspender a mamadeira assim que a criança seja capaz de beber em uma xícara. Além disso, devem fazer a higienização após a erupção dos dentes e utilizar flúor, caso a água não seja fluoretada; restringir o consumo de carboidratos; observar os primeiros sinais de cárie; e levar a criança ao dentista regularmente a partir dos primeiros meses de vida, principalmente entre 18 e 24 meses de idade $^{(16)}$.

É fundamental para a educação da criança de 0 a 4 anos de idade que esta seja condicionada em relação a ter uma alimentação saudável e hábitos de higiene oral adequados. Daí os pais serem tão importantes quanto os profissionais da área de saúde na educação de seus filhos, uma vez que são os pais, e em especial a mãe que amamenta que influenciam na formação de hábitos adequados ${ }^{(10)}$.

A família representa o núcleo mais primitivo, no qual se formam e se desenvolvem hábitos, atitudes e comportamentos que serão reproduzidos durante toda a vida(18). É importante a implantação de programas preventivos e educativos com gestantes, para que se possam introduzir bons hábitos desde o início da vida da criança(19). Nesse contexto, a educação em saúde é uma ferramenta disponível à equipe da Estratégia Saúde da Família (ESF), que deve disseminar noções de higiene bucal.

As ações de educação em saúde estão cada vez mais enfatizadas nas discussões acerca da qualidade da assistência prestada à população assistida pela Estratégia Saúde da Família (ESF). Desde 2000 o Ministério da Saúde com o intuito de ampliar o acesso dos usuários às ações básicas de saúde bucal, promoveu a inclusão da Saúde Bucal na ESF(34). Assim sendo, a Odontologia tem ganhado espaço no âmbito da ESF, tornando-se uma ferramenta importante, tanto preventiva quanto curativa(35).

Geralmente a Odontologia priorizava o atendimento a crianças a partir dos seis anos de idade, e as crianças de 0 a 5 anos e as gestantes não eram priorizadas. Atualmente constata-se que 
a prevenção das doenças bucais deve ser iniciada precocemente, de preferência durante a gestação. É nessa fase que a equipe odontológica da ESF deverá desenvolver ações junto aos pais visando promover a saúde bucal dos bebês( ${ }^{(36)}$. Eles devem ser envolvidos para que a criança seja acostumada precocemente ao cuidado com os dentes e boca, mantendo a saúde e prevenindo doenças( ${ }^{(35)}$.

Os profissionais da ESF tem buscado valorizar a assistência ao pré-natal, pois esses cuidados mostram repercussões positivas na saúde da criança. Dados do Ministério da Saúde, demostraram que, quando não existe assistência adequada no pré-natal, há um aumento alarmante na morbimortalidade infantil e quando a assistência ocorre, a morbimortalidade decresce acentuadamente(21).

Com relação aos hábitos alimentares, é essencial discutir com as grávidas a importância de uma boa nutrição durante a gestação, pois a dieta saudável pode influenciar a saúde geral e dentária da criança que vai nascer(20). Também se deve orientar que a cárie dental é uma doença infecciosa e transmissível, que pode acontecer em qualquer superfície do dente. Essa lesão pode ser variada desde apenas a perda de minerais até a destruição total da estrutura dentária(21). Dessa forma, a família deve estar atenta quanto ao aparecimento da doença.

As gestantes formam um grupo altamente suscetível a receber informações e a incorporar novas atitudes, buscando o máximo bem-estar a si mesmo e ao futuro filho. Nessa fase, elas incorporam as informações sobre saúde melhor do que em qualquer outro período de sua vida, constituindo-se em um grupo de especial atenção para educação em saúde (22).

A mãe tem papel fundamental na família, especialmente em relação às questões de saúde. Destaca-se a relevância de programas que venham a interferir na quebra da cadeia de transmissibilidade da cárie, a partir de medidas preventivo-educativas, de maneira que a mãe/gestante possa atuar como agente multiplicador de informações de promoção de sua saúde e da de sua família(23).

O profissional de odontologia apresenta uma função essencial ao influenciar positivamente na saúde sistêmica da gestante(24). Daí a necessidade das medidas educacionais e preventivas para as mães, pais e outros agentes envolvidos na educação da criança, visando minimizar os resultados adversos da gestação e o risco de cárie em seus filhos(25-27).

Para evitar a instalação de cáries em bebês, são necessários programas voltados para a promoção de saúde na primeira infância e para a manutenção da saúde bucal das crianças, uma vez que os hábitos alimentares adquiridos pelas crianças estão relacionados aos da mãe e ao com nível de conhecimento desta a respeito de sua saúde(28).

A mãe deve ter consciência da importância da saúde bucal não só de seu bebê, mas da sua própria saúde ${ }^{(26)}$. Se a gestante não compreende o conceito de saúde, ela não terá uma saúde bucal adequada e existirão dificuldades para realizar e praticar medidas de prevenção de doenças e promoção de sua saúde bucal, bem como para fazer com que seu filho cresça com essa mesma preocupação(29).

Apesar de a amamentação assumir características primárias para o desenvolvimento da doença cárie, essa prática não deve ser considerada o único fator comportamental de risco(17). Apesar do leite, mesmo sem açúcar, ser cariogênico, este também possui substâncias que podem proteger o dente contra as cáries, como o cálcio e o fósforo, que ajudam no processo de remineralização do esmalte, e a caseína, que fornece uma proteção orgânica, revestindo a superfície do esmalte ${ }^{(30)}$.

A doença cárie está relacionada a um processo de desmineralização e remineralização dos tecidos dentários (esmalte, dentina e cemento). Inicia-se com a desmineralização (perda de minerais), ocorrendo com a presença de bactérias na placa dental, que fermentam e produzem ácidos orgânicos, além de acarretarem a queda do $\mathrm{pH}^{(30)}$. Dessa forma, a higiene bucal deve ser praticada precocemente.

Quando não acontece uma remineralização (reincorporação dos minerais) e o processo de desmineralização está mais avançado, pode-se observar o aparecimento de manchas esbranquiçadas na superfície dentária. A mancha branca também é descrita como lesão inicial ou incipiente. Esse tipo de lesão pode estar inativa, mesmo estando presente há muito tempo no dente - assim, nem toda mancha esbranquiçada e opaca pode ser considerada como inicial ou incipiente(27).

Portanto, recomenda-se a visita frequente ao dentista para orientação, evitando, assim, o aparecimento desse tipo de lesão, já que a perda precoce dos dentes decíduos anteriores, além de afetar psicologicamente a criança, pode 
desenvolver deglutição e fonação atípicas, provocar atraso na erupção dos dentes permanentes e dificultar a alimentação, além de ocasionar prováveis problemas ortodônticos ${ }^{(11)}$.

Estudo da relação entre amamentação e cárie verificou que a lactose encontrada no leite humano é responsável pelo aparecimento de lesões cariosas e que o leite humano possui um potencial cariogênico superior ao do leite bovino(31). Entretanto, outro estudioso(32) julgou essa diferença insignificante em termos de cariogenicidade. Outro estudo comprovou que não há relação significativa entre amamentação e cárie precoce na infância ${ }^{(33)}$. Os profissionais da ESF devem estar atentos, pois os pais quase sempre desconhecem a época ideal para $o$ desmame, a cariogenicidade do leite materno e a necessidade de higienização dos dentes após a amamentação(11).

Portanto, não há evidências científicas que comprovem que o leite materno possa estar associada com o surgimento de cárie sendo essa relação complexa e confundida por muitas variáveis, principalmente infecção por estreptococo mutans, hipoplasia do esmalte, ingestão de açúcares em suas mais variadas formas e condições sociais representadas pela educação e nível socioeconômico dos pais. Portanto, a amamentação noturna não deve ser desencorajada, assim como nenhuma forma rígida de conduta alimentar deva ser adotada em relação à criança em aleitamento ${ }^{(11)}$.

A importância do leite materno nos primeiros meses de vida é indiscutível, não havendo comprovação científica que associe a cárie precoce ao aleitamento materno, portanto a amamentação noturna não deve ser desencorajada, ao contrário, deve-se estimular o aleitamento materno exclusivo até os 6 meses, mantendo-o pelo menos até os 2 anos de idade ou mais, sem restrições de horários ou turnos, não se esquecendo da importância da higiene oral frequente ${ }^{(11)}$.

\section{Conelusão}

A leitura dos trabalhos da presente revisão contribuíram para trazer uma visão das principais causas da cárie rampante de mamadeira, as consequências e uma visão sobre a atuação da Estratégia Saúde da Família sobre o problema, bem como uma visão dos métodos de controle e combate à doença.
Conscientes da importância dos dentes decíduos para o adequado desenvolvimento e crescimento dos arcos maxilares, a organização correta da oclusão e a função mastigatória e fonoarticulatória, deve-se evitar sua perda precoce, pois as consequências podem ser desastrosas para a dentição permanente.

Ao analisar a literatura sobre o assunto, conclui-se que os autores são unânimes em afirmar que as cáries rampantes constituem um problema de difícil solução após sua instalação.

Portanto, com base nesse fato, é pertinente o desenvolvimento de programas de orientação às mães e familiares, no sentido de prevenir essa patologia, que tão comumente afeta os lactentes, como afirmam vários autores.

Propõe-se, então, além da orientação aos pais sobre higiene, algumas medidas preventivas para minimizar o aparecimento de cáries rampantes nas crianças, como a higienização bucal após cada mamada; o alerta sobre o efeito das mamadas noturnas nos dentes dos bebês; o desencorajamento do uso de mamadeiras e chupetas açucaradas; a instauração da profilaxia profissional em idade precoce por, pelo menos, uma vez ao mês; a utilização inteligente do flúor e de vernizes fluoretados como agentes protetores; o uso de cimentos de ionômero de vidro como material adequador do meio bucal; o emprego de agente cariostático, como paralisante das lesões cariosas; e a reabilitação bucal após o controle da cárie rampante.

\section{Referências}

1. Gomes A. Práticas de aleitamento materno em crianças menores de um ano em municípios de Minas Gerais [Internet]. 2011. 100f. Dissertação (mestrado). Minas Gerais: Universidade Federal de Minas Gerais; 2011 [citado 2014 Abr 23]. Disponível em: http://www.bibliotecadigital.ufmg.br/dspace/handl e/1843/BUOS-8LBL5A

2. Nelson-Filho P, Queiroz AM, Mussolino ZM, Assed S. Avaliação dos hábitos alimentares em crianças portadoras de Cárie de mamadeira. J Bras Odontopediatr Odontol Bebe. 2001;4:30-4.

3. Ditterich RG, Romanelli MV, Rastelli MC, Wambier DS. Cárie de acometimento precoce: uma revisão. CiencBiol Saúde. 2004; 10(3/4):33-41.

4. Narvai PC. Saúde bucal coletiva: caminhos da odontologia sanitária à bucalidade. Rev Saúde Pública [Internet]. 2006 [citado 2014 Abr 23]; 40(n. esp):141-7. Disponível

http://www.scielo.br/pdf/rsp/v40nspe/30633

5. Barros SG, Castro Alves A, Pugliese LS, Reis SRA. Contribuição ao estudo de cárie em crianças de 0-30 meses. Pesq Odontol Bras. 2001; 15(3):215-22. 
6. Shiroma E. Diagnóstico in vitro de cárie oclusal com laser diodo em dentes submetidos à desmineralização e remineralização [Internet]. Dissertação (mestrado). Taubaté: Universidade de Taubaté; 2006 [citado 2014 Abr 23]. Disponível em: http://www.dominiopublico.gov.br/pesquisa/Detalh eObraForm.do?select_action $=\&$ co_obra $=28202$

7. Milfont DA, Medeiros EB, Duarte RC. Prevalência de cárie e sua relação com o tipo de aleitamento em bebês da Maternidade Cândida Vargas. RGO. 2009; 57(4):431-6.

8. Abdo RC, Nunes DN, Salles V. Cárie rampante, etiologia e soluções de tratamento [Internet].RevUn Alfenas. Alfenass. 1998; 4:159-63. [citado 2014 Abr 23]. Disponível em: http://www.unifenas.br/pesquisa/revistas/downloa d/ArtigosRev2_98/pag159-163.pdf

9. Soares IMV, Silva AMRB, Moura LFAD, Lima MDM, Sousa Neto OB, Moura MS. Conduct of pediatricians in relation to the oral health of children. RevOdontol UNESP [Internet]. 2013 [citado 2014 Abr 23]; 42(4):26672 Disponível em: http:/ / www.scielo.br/scielo.php?pid=S180725772013000400006\&script=sci_arttext

10. Ramos BC, Maia LC. Cárie tipo mamadeira e a importância de saúde bucal em crianças de 0 a 4 anos. Rev Odontol Univ São Paulo [Internet]. 1999 [citado 2014 Abr 23]; 13(3):303-11. Disponível em: http://www.scielo.br/scielo.php?script=sci_arttext\&p id=S0103-06631999000300016

11. Ribeiro EMN, Ribeiro SAM. Aleitamento materno e cárie do lactente e do pré-escolar: uma revisão crítica. Jornal de Pediatria [Internet]. 2004 [citado 2014 Abr 23]; 80(5 Supl.):S199-210. Disponível em: https://www.nescon.medicina.ufmg.br/biblioteca/re gistro/referencia/0000000061

12. Award LP, Eleiser R. Cárie provocada por leite materno: revisão e apresentação de caso clínico. Rev Bras Odontol. 1984; 41(2):22-4.

13. Kroll RG, Stone JH. Nocturnal bottle feeding as a countributory cause of rampant dental caries in the infant and young child. Journal Dent Child. 1967; 34(6):454-9.

14. Gardner DE, Norwood JR, Eisenson JE. At will breast feeding and dental caries: four case reports. Journal Dent Child. 1977; 44(3):186-91.

15. Abbey LM. Is breast feeding a likely cause of dental caries in young children? Journal Amer Dent Assoc. 1979; 98(1):21-3.

16. Kotlow LA. Breast feeding: a cause of dentalcariesIn children. Journal dent Child. 1977; 44(3):192-3.

17. Ripa LW. Nursing caries: a comprehensive review. Pediatr Dent. 1988; 10(4):268-82.

18. Costa ICC. Atenção odontológica a gestantes na concepção médico-dentista-paciente: representações sociais dessa interação. RPG. 2002; 9(3):232-43.

19. Corsetti LO, Figueiredo MC, Duli CA. Avaliação do atendimento para gestantes nos serviços públicos de Porto Alegre - RS, durante o período pré-natal. Revista da ABOPREV. 1998; 1(1):9-15.

20. Freitas DA, Antunes SLNO, Caldeira AP. Saúde bucal de gestantes: enfoque em saúde pública. EFDeportes.com, Revista Digital. Buenos Aires - Año 16 - No 158 - Julio de 2011. Acesso em 233 de abril de 2014. Disponível em: http:/ / www.efdeportes.com/
21. Konishi MFCC. Odontologia intra-uterina: a construção da saúde bucal antes do nascimento. Rev Bras Odontol. 2002;59(5):294-5.

22. Menoli APV, Frossard WTG. Perfil de médicos ginecologistas/ obstetras de Londrina com relação à saúde oral da gestante. Semina. 1997; 18:34-42.

23. Costa ICC, Marcelino G, Berti MG, Saliba NA. A gestante como agente multiplicador de saúde. RPG. 1998; 5(2):87-92.

24. Fass EN. Is bottle feeding a factor in dental caries? Journal Dent Child. 1984; 29(4):245-51.

25. Goldie MP. Oral health care for pregnant and postpartum women. Int J DentHyg. 2003; 1(3):174-6.

26. Menino RTM, Bijella VT. Necessidades de saúde bucal em gestantes dos núcleos de saúde de Bauru. Conhecimentos com relação à própria saúde bucal. Revista da Faculdade de Odontologia de Bauru. 1995; 3(1/4):5-16.

27. Mills LW, Moses DT. Oral health during pregnancy. MCN Am J Matern Child Nurs. 2002; 27(5):275-80; quiz 281.

28. Carvalho GD. Amamentação: Uma avaliação abrangente II.Rev Secret Saúde. 1997; 4(28):8-10.

29. Martins VF. A importância da odontologia para as gestantes. Rev APCD. 2004; 56(2):7-9.

30. Ferreira CD. Relação entre questões nutricionais e cárie dentária [Internet]. Lume - Repositório Digital da Universidade Federal do Rio Grande do Sul; 2008 [citado 2014 Abr. 23]. Disponível em: http://www.lume.ufrgs.br/handle/10183/15415

31. Roberts GJ. Is breast feeding a possible cause of dental caries? J Dent. 1982; 10(4):346-52. Disponível em: http://www.sciencedirect.com/science/article/pii/0 300571282900306

32. Seow WK. Biological mechanisms of early childhood caries. Community ent Oral Epidemiol. 1998; 26(1 Suppl): 8-27.

33. Jin BH, Ma DS, Moon HS, Paik DI, Hahn SH, Horowitz AM. Early childhood caries: prevalence and risk factors in Seoul, Korea. J Public Health Dent. 2003; 63(3):183-8.

34. Ministério da Saúde (BR). SIAB. Sistema deinformação da Atenção Básica. Brasília: Ministério da Saúde; 2012.

35. Pinto VG. Saúde bucal coletiva. 4 ed. São Paulo: Ed.Livraria Santos; 2000.

36. 36.Faria-Junior LJ. Dicas de saúde: odontopediatria. Centro de Estudos da Disfunção Dento Articular (CEDDA). 2006. [citado 2014 abr 23]. Disponível em: URL: http://www.uraonline.com.br/saude/saude06/ odontopediatria.html 